\section{Interventional Pain Physician What's in a name?}

\author{
Laxmaiah Manchikanti, MD
}

Since its annual meeting in November 1999, the Association of Pain Management Anesthesiologists (AOPMA), has been faced with the challenge of changing its name. Association of Pain Management Anesthesiologists: is it inclusive or exclusive? Most anesthesiologists say it is inclusive. However, interventional pain physicians from other specialties say it is exclusive. After much debate and consideration of dissenting opinions, the AOPMA Board of Directors decided to change the name to the American Society of Interventional Pain Physicians (ASIPP). As of now, it is only a proposed change. However, it appears to be certain that the name change will take place.

Now the question is: what is in a name? The next question is: what is interventional pain medicine? Furthermore, who is an interventional pain physician? Is there a crisis in recognition for interventional pain physicians and interventional pain medicine, or does the crisis extend to the subspecialty of pain management or medicine itself? Let us explore various aspects of the history of the pain management or medicine, the role of the physician in pain management, the role and place of the interventional pain physician in the hierarchy of modern medicine, board certification(s) in pain management/medicine, representation, and the role of the AOPMA or the future ASIPP in interventional pain management in coming years.

"Pain," as Albert Schweitzer said in 1953, "is a more terrible Lord of mankind than even death itself." Twenty years later, John Bonica said: "Pain is the most pressing

From Pain Management Center of Paducah, Paducah, KY. Dr. Manchikanti is medical director of Pain Management Center of Paducah and the President of the Association of Pain Management Anesthesiologists. Address correspondence: Laxmaiah Manchikanti, MD, 2831 Lone Oak Road, Paducah, KY 42003 issue of modern times." American Medical Association (AMA) News Correspondent Janice Perrone wrote: “Although the medical profession's failure to provide adequate pain relief is a major impetus for the right-to-die movement, chronic pain still tends to be the Rodney Dangerfield issue to all but its sufferers." Dr. Regina Benjamin told reporters in a special AMA press briefing: "Pain gets no respect from insurers, families, and too often, from physicians. Pain can be identified, treated, and controlled from the pain of a fall off a bike to pain during the end of life care." Professor Gene Bernard of the French Academy hit a nerve when he stated, "Medicine has changed more in the last fifty years than in the preceding fifty centuries. However, pain has attracted less attention. Pain has been looked upon as a symptom and has not been the center of attention for clinicians or researchers." Albert Schweitzer also wrote: “ . . . . we must all die. But that I can save a person from days of torture, that is what I feel is my great and ever new privilege...."

Even though medicine has existed since the appearance of humankind on earth, scientific medicine represents a relatively recent achievement. While pain management is a relatively new specialty, it is difficult to understand when pain management started to be dominated by cognitive behavioral pain medicine and the representation of the interventional pain physician was lost. Between 1930 and 1945, significant developments occurred in pain management. The French Surgeon, Leriche was the first to identify chronic pain as a disease state (1). Subsequently, in 1943, Livingston (2) published a memorable text in which he explained pain mechanisms in causalgia and their related states. The study of diagnosis and relief of pain was stimulated by these writings, and sympathetic block anesthesia became a popular treatment of pain involving nerve tracts, as well as pain of obscure origin. In subsequent years, Woodbridge (3), Ruth (4), Mandle (5), Rovenstine and Wertheim (6), and many other anesthesiologists popularized diagnostic and therapeutic nerve block techniques in pain control (7). Beecher's (8) publications during 
World War II persuaded the medical community that the experience of pain is not always proportional to tissue damage and that many other factors modify pain. During World War II, Bonica (9) and Alexander (10) also developed broad views of pain and its management. Bonica (9) and Alexander (10) postulated that chronic pain is best managed by a team of organized specialists representing different disciplines who are knowledgeable and interested.

In the era of post World War II, many pain clinic facilities in the United States were organized mainly by anesthesiologists, who predominantly used nerve block techniques for pain control. In 1946 Bonica started implementing the concept of a team approach to the management of chronic pain patients (9). However, it was not until 1960 that he developed one of the first multidisciplinary pain centers in conjunction with a neurosurgeon and a member of the faculty of the school of nursing.

In 1976 the Medical World News listed only 17 pain clinics in the United States. However, 10 years later, the American Society of Anesthesiologists (ASA) listed over 300 pain control facilities (11). In 1987 it was estimated that there were about 1,200 pain clinics in the United States. By the end of the century, it appeared that the number of clinics proclaimed as pain clinics and the number of physicians declared as pain physicians has exceeded 5,000 in the United States. While the rise in the number of pain treatment centers in the United States reflects increasing awareness of chronic pain and its impact on our society, the last decade also saw major factions in the pain management community (12-20). Even though anesthesiologists continue to dominate the scene, almost $25 \%$ of physiatrists and some radiologists, neurologists, psychiatrists, neurosurgeons, and other specialists have joined the ranks of the pain management community. However, it has not stopped with physicians but also extended to a multitude of other providers.

Along with this, numerous organizations representing pain physicians and practitioners have developed. In the United States these include the International Association for the Study of Pain, American Pain Society, American Academy of Pain Medicine, American Academy of Pain Management, American Society of Regional Anesthesia and Pain Medicine, International Spinal Injection Society, International Association for the Study of Headache, and the National Forum of Independent Pain Clinicians; various societies representing the primary specialties such as anesthesiology, physical medicine and rehabilitation, neurology, psychiatry, and radiology; societies with special interest groups, such as the North American Spine Society; multiple regional and local associations and, finally, the Association of Pain Management Anesthesiologists. The primary purpose of most organizations is the education of either pain management professionals or a primary core specialty such as anesthesiology, physiatry, radiology or spine, except for the Association of Pain Management Anesthesiologists, which has the primary purpose of preserving quality interventional pain management. This is not to say that AOPMA neglects education. It continues to focus on education not only medically but also in practice management. Similarly, there are numerous pain journals, even though there was only one journal dedicated to pain in 1974. These include Pain, Clinical Journal of Pain, Journal of Pain, Pain Forum, American Journal of Pain Management, Regional Anesthesia and Pain Medicine, Pain Digest, Pain Medicine, Pain Physician, and a few other journals in progress, apart from the interventional and primary journals of anesthesiology, physiatry, radiology, orthopedic surgery, and the spine.

Pain management, as a specialty, has essentially moved away from its origins in multidisciplinary pain management to a cognitive behavioral model of pain medicine, leaving interventional pain physicians struggling to practice in a multidisciplinary setting.

The American Medical Association's advertisement asks physicians, "While you are looking out for your patients, who is looking out for you?" Hierarchy and the goodold-boy network are dominant forces and a common phenomenon in modern medicine, starting with the "establishment" of the American Medical Association. Most organizations and physician groups promote and represent their own interests, and rightfully so. Thus, a hierarchy originates within the establishment of the AMA, followed by surgeons, then by powerful subspecialists in internal medicine, and remotely followed by other specialists. A common experience of all of us in doctor's lounges is that the dominant voices heard are those of the surgical specialists mixed with constant complaints by the nonsurgical specialists. In addition, in medical specialties, there are a multitude of groups based on either procedural specialty or cognitive medical services. These groups are followed, of course, by anesthesiologists, pathologists, and radiologists. The last specialty — if it still exists — is that of pain medicine consisting of a heterogenous group of physicians.

Pain medicine has largely been dominated and essentially taken over by physicians who believe in the 
biopsychosocial model. Therefore management is predominantly by way of biopsychosocial approaches. We continually read and hear about how pain medicine is ignored, how opinions of pain management specialists are squashed, and how medicine is dominated by the established groups. However, when the issue comes to interventional pain management, an interventional pain physician stands alone while the so-called traditional pain management community, along with some other physicians in the community, oppose them or only provide lukewarm support to interventional pain medicine. It is surprising to note that one of our oldest and largest societies (13) insists pain is always subjective and always a psychological state. In addition, low back pain is not considered as a disease or disorder. Philipp Lippe, while he was executive vice president of the American Board of Pain Medicine, wrote the following about pain medicine:

\begin{abstract}
"A unified, non-fragmented specialty of pain medicine is essential to the medical profession and to society. To remain viable, the specialty depends upon pain physicians to support research and education in the field. The field of pain medicine is primarily a non-procedural specialty (emphasis added). It is not in conflict or in competition with anesthesiologists who sub-specialize in pain management nor, for that matter, it is not in competition with any other primary specialty that may choose to develop sub-specialty expertise in pain management."
\end{abstract}

As Dr. Lippe states, and I emphasize, the field of pain medicine is primarily a non-procedural specialty. Furthermore, the statement that it is not in conflict or in competition with anesthesiologists who subspecialize in pain management, essentially excludes anesthesiologists from the specialty of pain medicine. At best, it accepts them as outsiders, even though both the American Academy of Pain Medicine and the American Board of Pain Medicine are predominantly composed of anesthesiologists. However, this issue goes beyond anesthesiologists as pain management specialists. It hits on all interventional pain specialists from all specialities. Thus, while the entire community of pain management societies focuses on non-procedural management of pain, other specialities focus on their primary specialities, such as anesthesiology, physiatry, radiology, and spine surgery. I do not have any quarrel with regards to the support of these organizations and of their views. However, arguments do arise when they proclaim that they are the stewards of pain management by excluding the majority of the pain management community. While the controlling members of any organization can proclaim their loyalty to any value or belief, they should be in agreement with the views of the majority of their membership. Many members of the establishment claim that their views are based upon the misuse of interventional pain management. Once again, they are justified in doing so if this is true of the majority of the members of the interventional pain management community. But, the quoted examples are only anecdotal and without evaluation of evidences; snapshots; biased, unproven, unconfirmed opinions. In legal terminology, this is called hearsay or lack of evidence; in journalistic terms, un-newsworthy publication since because it is unconfirmed. But in pain medicine, it appears to be the mainstay. Thus, once again, the power of the establishment goes on. While I totally agree with those pain medicine specialists who observe that there is not a preponderance of evidence supporting interventional pain management, I also would like to point out that there is no such evidence supporting either functional rehabilitation or behavioral approaches. One may also argue that the costs of functional rehabilitation programs or biopsychosocial pain management programs may not be any less than interventional pain management programs, but any differences in cost effectiveness or outcomes among these approaches are yet to be proven. In addition, one may argue that the lack of evidence in support of interventional pain management is based partly upon, once again, the influence of a multitude of pain journals and other journals that are dominated by an establishment that typically happens to be a small group of academics who control most of the published work of pain and medical journalism. The next issue, unfortunately, comes from inside of the establishment of the interventional pain physician community itself. For no apparent reason, some physicians feel that they should control the practice of interventional pain management, even though they have neither pioneered a technique, nor attempted to preserve interventional pain management. While I understand their philosophy and passion for their beliefs, I am somewhat disturbed by their apparent lack of understanding of the present day issues of interventional pain management that are inextricably intertwined with the decision-making processes in the political-medical bureaucracies.

Obviously, the next issue of controversy extends to the claims of each organization and society regarding not only their contributions to pain medicine, but to their efforts to 
preserve pain medicine as such or interventional pain medicine in the new millennium. It is a fact beyond any question that the surge of pain societies, pain certifications, and journals has provided greatly increased recognition for pain management. But this recognition has not always been positive. In spite of the efforts of all of these organizations, pain medicine has been attracting negative publicity. In general, this negative publicity of pain medicine cannot be accurately blamed on any particular group, but it does appear that interventional pain management has been given a somewhat negative connotation due to the criticism of behavioral specialists.

Another major achievement of pain medicine in the last decade has been the creation of board certification by the American Board of Pain Medicine and the American Academy of Pain Management. While these board certifications offer a sense of pride and joy, and occasional recognition, their real values have yet to be determined because these boards are not recognized by the American Board of Medical Specialities (ABMS). And it appears that this will not happen in the near future. It is of interest to note ABMS, an umbrella organization currently has 24 primary boards, which issue 38 general certificates, and 72 subspeciality certificates. Although an exact count is not available, it is estimated that non-ABMS organizations providing board certifications exceed 150 . In addition, the need for such speciality boards has been questioned as it is not only duplicative, expensive, and confusing, but redundant because subspeciality certifications in pain management are available through three ABMS-recognized speciality boards; namely, anesthesiology, physical medicine and rehabilitation, neurology and psychiatry. Thus, I have not embraced the idea of the creation of an interventional pain medicine board. Another important point to be mentioned here is that board certifications can be obtained from a number of organizations (over 150) at an annual cost of $\$ 500$ to $\$ 1,000$ even though few have incorporated strict standards. These organizations can designate any physician not only as a specialist in pain management, but also in disability evaluation, forensic medicine, psychology, independent medical evaluation, forensic psychology, many surgical specialities, and other designations. However, any number of these certificates fail to provide protection of any kind to the practice of pain management and thus jeopardize the very practice of interventional pain management.

Another achievement of many pain societies - so members are told - is that of legislative representation, lobbying, and the protection of the interests of pain manage- ment. Thus far, this definitely has not included interventional pain management on any of these fronts at any reasonable level. Sadly, it also has not provided any positive impact on the speciality of pain medicine itself. Finally, a multitude of societies have attempted and continue to attempt to provide practice guidelines. Thus far, the American Society of Anesthesiologists is the only society that has published its guidelines, which, despite publicity, have not been widely utilized because these guidelines do not provide practical guidance to patients, physicians, governmental agencies, or insurers, despite the time and money put into developing these guidelines (21). Other societies are developing comprehensive guidelines, though a few joint ventures have produced some useful guidelines.

Having challenged the appropriateness of the dominance of the biopsychosocial model in pain management, the value of behavioral therapy should not be discounted (22). The need for psychiatric, psychological, and behavioral assessment and management is not only valid but essential in many cases, though not for the reasons assumed (22). Biopsychosocial facilitation of pain, psychological issues, symptom magnification, non-physiological signs, and interventional pain management are buzzwords in today's world of pain management. As it is well-recognized, the concept of chronic pain is beset with controversies starting with its very definition. While chronic pain has several definitions, the terminology itself ranges from chronic pain, recurrent pain, and persistent pain, to chronic pain syndrome. However, chronic pain and chronic pain syndrome are separate and distinct entities (23-25). As it is well-known, chronic pain syndrome is associated with major psychological and behavioral problems with or without a physical problem and encompassing eight d's: duration, dramatization, diagnostic dilemma, drugs, dependency, depression, disuse, and dysfunction.

While recurrent pain is the main focus of chronic pain syndrome, chronic pain may be associated with psychological problems, such as depression, generalized anxiety disorder, and additional behavioral problems; in contrast to chronic pain, chronic pain syndrome is a malevolent and destructive force $(24,25)$. In addition, chronic pain syndrome is a self-sustaining, self-reinforcing, self-regenerating process, with markedly- enhanced perception and with maladaptive and grossly disproportional pain-related behavior. A preponderance of evidence shows that chronic pain syndrome is neither a common phenomenon nor an entity (23-28). Commonly, physicians presume symptom magnification, malingering, and deception in these patients based on the presentation of non-physiological signs and 
inappropriate determinations of these signs. Symptom magnification is defined as "a self-destructive, sociallyreinforced behavioral response pattern, consisting of reports or displays of symptoms, which function to control the life or circumstances of the sufferer" by Matheson (29). Symptom magnification is the most abused and misused diagnosis and terminology, not only in the today's impairment evaluation and disability medicine, but also in pain medicine (30).

The assessment process of symptom magnification is prolonged and time-consuming, involving detection of various signs and symptoms (30). Instead, many physicians confer the diagnosis of symptom magnification based on non-physiological symptoms and signs of Waddell et al $(31,32)$. Waddell's signs and symptoms are generally misunderstood, thus wrongly-applied and unjustly accuse the patient of committing fraud; while, in fact, the evaluating physician may, at best, be ignorant and, at worst, committing fraud (31-34).

Some authors concluded that the presence of persistent high levels of inappropriate signs would predict the failure of interventional pain management based on the belief that the outcome would depend the patient's biopsychosocial inability for self-facilitated improvement, and thus suggested that somatic treatment does not work (35-37). However, Wallis and colleagues (38) demonstrated, to the surprise of many behavioral specialists, that after radiofrequency facet denervation, pain relief was achieved. Those patients did not only return to work but also resolved all the psychological problems, making the extraordinary attention on psychological status questionable. In addition, Manchikanti et al (39) failed to show any correlation between non-physiological symptoms (Waddell's) symptoms, non-physiological (Waddell's) signs, somatization disorder, and presence or absence of facet joint mediated pain confirmed by controlled double diagnostic blocks. Extensive review of the determination of causal risk factors and the epidemiology of low back pain showed no statistically significant causal factors, even though these reviews showed multiple, probable, and possible factors, with psychosocial factors falling into the probable category (40). Thus, we arrive at the rationale for diagnostic neural blockade, which stems from the fact that neither clinical features or imaging nor neurophysiologic studies permit the accurate diagnosis of the causation of spinal pain in the majority of patients in the absence of disc herniation and neurological deficit (23). Further recurring facts show that the overall rate of inaccurate or incomplete diagnosis in patients referred to pain treatment centers ranges from $40 \%$ to $67 \%$, the incidence of psychogenic pain is only approximately one in 3,000 patients, and the presence of organic origin of pain can be demonstrated in $98 \%$ of the cases that are mistakenly branded as psychosomatic cases $(22,23,27,28)$. However, in spite of all the above factors, the most compelling reason for diagnostic blocks is that chronic low back pain is a diagnostic dilemma in $85 \%$ of the patients, even in experienced hands with all the available technology (23, 41). On the other hand, it has been determined that utilizing alternative means of diagnosis, including precision diagnostic blocks in cases where there is a lack of definitive diagnostic radiological or electrophysiologic criteria, can enable an examiner to identify the source of pain in the majority of patients, reducing the proportion of patients who cannot be given a definite diagnosis from $85 \%$ to $35 \%$ or even as low as $15 \%$ (23). Similarly, the rationale for other therapeutic interventional techniques, including neural blockade in the spine, is based upon several considerations:

The cardinal source of chronic spinal pain -
namely discs and joints - is accessible to
neural blockade.
Removal or correction of structural abnormali
ties of the spine may fail to cure and may even
worsen painful conditions.
Degenerative process of the spine and the
origin of spinal pain are complex.
The effectiveness of a large variety of thera
peutic interventions in managing chronic spinal
pain has not been demonstrated conclusively.

Cost effectiveness studies obviously provide variable results. As shown in Figure 1, cost effectiveness of interventional pain management is comparable to, not only other medical treatments, but also surgical management $(23,42-47)$.

As John F. Kennedy once said, "Ask not what your country can do for you, but ask what you can do for your country." Inspired by these selfless words, AOPMA has developed its own agenda of preservation of interventional pain management and the practice of interventional pain management. In the short period of its existence, AOPMA has gained national support and attention, not only from patients and physicians, but also from legislators and government. AOPMA also published its practical, concise, comprehensive guidelines for the practice of interventional pain management (23). 
Fig. 1: Cost effectiveness of selective therapies per quality-adjusted year of life gained
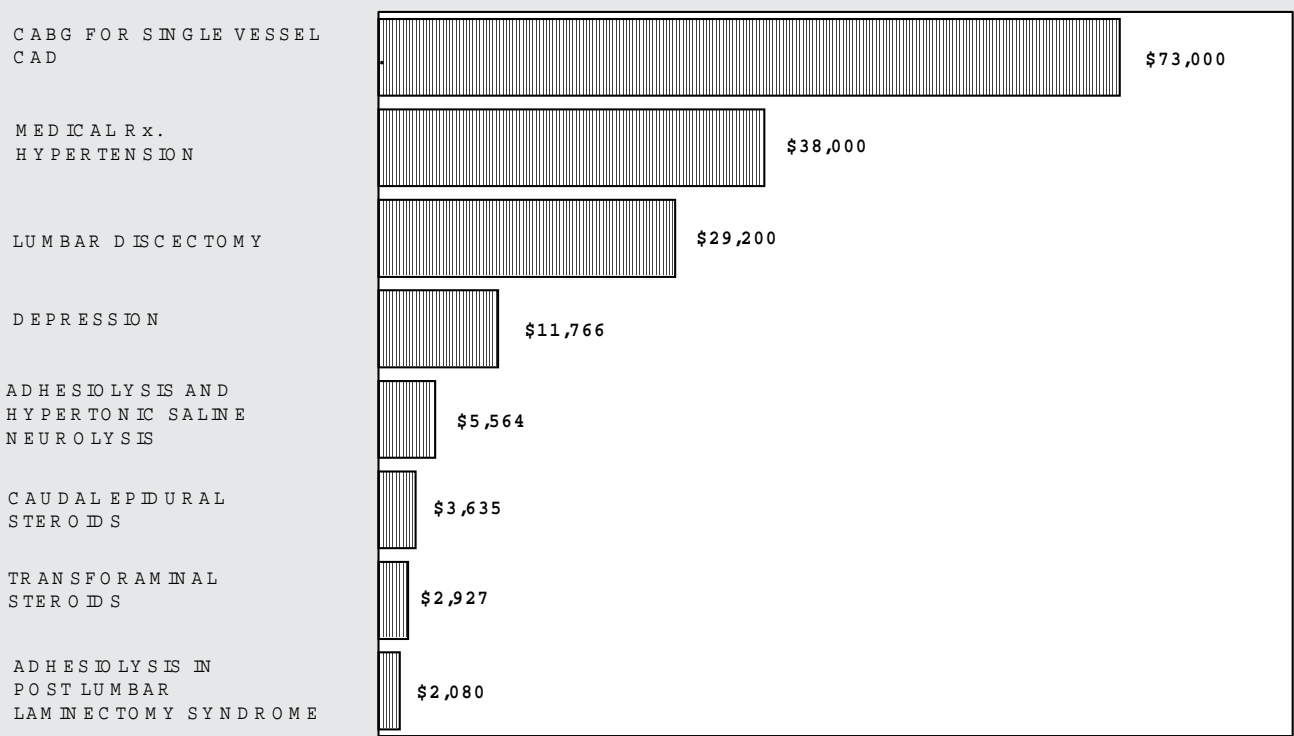

Figure reproduced with permission from Manchikanti et al (23). Data adapted and modified from Hopwood (42), Malter et al (43), Lave et al (44), and Manchikanti et al (45-47)

$\mathrm{CABG}=$ Coronary artery bypass graft $\mathrm{CAD}=$ Coronary artery disease.

In summary, the "establishment" of medicine is enormous. But the huge "establishment" of pain medicine is essentially uninformed, non-responsive, and unsympathetic to the cause of interventional pain management, understandingly so because of their philosophy, beliefs, and passion (48). While this path is unfruitful to our cause, it is probably wise to support these organizations, as they may provide global benefits to the pain management community. Thus, the efforts of the Association of Pain Management Anesthesiologists in the past, present, and future are more important than ever before in the preservation of the identity of the interventional pain physician and practice of interventional pain medicine itself.

\section{REFERENCES}

1. Leriche R. The Surgery of Pain. Baltimore, Williams \& Wilkins Co., 1939.

2. Livingston WK. Pain mechanisms. Physiologic interpretation of causalgia and its related states. New York, MacMillan Publising, 1943.

3. Woodbridge PD. Therapeutic nerve block with procaine and alcohol. Am J Surg 1930; 9:278-288.
4. Ruth H. Diagnostic, prognostic, and therapeutic block. JAMA 1934; 102:419.

5. Mandle F. Di paravertebrale blockade. Vienna, Springer, 1938.

6. Rovenstine EA, Wertheim HM. Therapeutic nerve block. JAMA 1941; 117:1599-1603.

7. Raj PP. History of pain medicine. Pain Digest 1995; 5: 198-205.

8. Beecher HK. Pain in men wounded in battle. Ann Surg 1946; 123:96-105.

9. Bonica JJ. Evolution of multidisciplinary/interdisciplinary pain programs. In Aronoff GM (ed). Pain Center: A Revolution in Health Care. New York, Raven Press, 1988.

10. Alexander FAD. The control of pain. In Hale DE (ed). Anesthesiology. Philadelphia, FA Davis, 1954.

11. American Society of Anesthesiologists. Directory of Pain Clinics. Park Ridge, American Society of Anesthesiologists, 1977.

12. Stanton-Hicks M. Rationale and management of chronic pain. Pain Digest 1995; 135-139.

13. Morris DB. An invisible history of pain: Early $19^{\text {th }}$ century Britain and America. Clin J Pain 1998; 191196. 
14. Rathmell JP, Patchin RJ. Controversies in pain management: Ethics in business practice. ASA newsletter 1999; 63 (10):2-8.

15. Somerville J. Pathetic ethics regarding pain practices. ASA newsletter 2000; 64 (1):31-32.

16. Parris WCV. Certification of pain specialists. Pain Digest 1992; 2:281-284.

17. Parris WCV. What is new and on the horizon in pain management. ASA newsletter 1999; 63 (10):16-18.

18. Cope DK. The new physician: Investigator, administrator, team player. ASA newsletter 1999; 63 (10):1415 .

19. Chen RB. Training the pain physician of tomorrow. ASA newsletter 1999; 63 (10):12-13.

20. Decker MJ. Imagine: An opportunity to create a pain medicine center. Pain Medicine 1999; 2 (1):2-6.

21. Task Force on Pain Management. Practice guidelines for chronic pain management. A report by the American Society of Anesthesiologists Task Force on Pain Management, Chronic Pain Section. Anesthesiology 1997; 86:995-1004.

22. Dotson, D. Why not relief? Pain Physician 2000; 3:65-68.

23. Manchikanti L, Singh V, Bakhit C, et al. Interventional techniques in the management of chronic pain: Part 1.0. Pain Physician 2000; 3:7-42.

24. Pain. Guides to the evaluation of permanent impairment. American Medical Association: Fourth Edition. Chicago, 1993:PP303-311.

25. Merskey H, Bogduk N. Classification of chronic pain: Descriptions of chronic pain syndromes and definitions of pain terms. Second Edition. Seattle, IASP Press, 1994.

26. Corran TM, Farrell MJ, Helme RD et al. The classification of patients with chronic pain: Age as a contributing factor. Clin J Pain 1997; 13:207-214.

27. Hendler NH, Bergson C, Morrison C. Overlooked physical diagnoses in chronic pain patients involved in litigations. Part 2. Psychosomatics 1996; 37:509517.

28. Hendler NH, Kolodny AL. Using medication wisely in chronic pain. Patient Care 1992; May 15: 125.

29. Matheson, L. Symptom magnification syndrome structured interview. Rationale and procedure. J Occup Rehab 1991; 1:43-55.

30. Manchikanti, L. Impairment Evaluation in Pain Management. Pain Physician 2000; 3: 201-217

31. Waddell G, McCulloch JA, Kummel E et al. Nonorganic physical signs in low back pain. Spine 1980; 5:117-125.

32. Waddell G, Main CJ, Morris EW et al. Chronic lowback pain, psychologic distress, and illness behavior. Spine 1984; 9:209-213.

33. Main CJ, Waddell G. Behavioral responses to examination. A reappraisal of the interpretation of “nonorganic signs." Spine 1998; 23:2367-2371.
34. Maruta, T, Goldman S, Chan CW et al. Waddell's nonorganic signs and Minnesota multiphasic personality inventory profiles in patients with chronic back pain. Spine 1997; 22:72-75.

35. Lilius G, Laasonen EM, Myllynen P et al. Lumbar facet joint syndrome. A randomized clinical trial $J$ Bone Joint Surg 1989; 71-B:681-684.

36. Lilius G. Harilainen A, Laasonen EM et al. Chronic unilateral low-back pain. Predictors of outcome of facet joint injections. Spine 1990; 15:780-782.

37. Lilius G, Laasonen EM, Myllynen P et al. Lumbar facet joint syndrome. Significance of non-organic signs. A randomized placebo-controlled clinical study. Rev Chir Orthop 1989; 75:493-500.

38. Wallis BJ, Lord SM, Bogduk N. Resolution of psychological distress of whiplash patients following treatment by radiofrequency neurotomy. A randomized, double-blind, placebo-controlled trial. Pain 1997; 73:15-22.

39. Manchikanti L, Pampati V, Fellows B et al. The inability of the clinical picture to characterize pain from facet joints. Pain Physician 2000; 3:158-166

40. Manchikanti L. Epidemiology of low back pain. Pain Physician 2000; 3: 167-192

41. Waddell G, Turk DC. Clinical assessment of low back pain. In: Turk DC, Melzack R (eds). Handbook of pain assessment. First Edition. New York, The Guilford Press, 1992; 15-36.

42. Hopwood M. Outcomes assessment in pain management. In: Abram SE (Ed). Pain Management. Philadelphia, Churchill-Livingston, 1998, pp14.1-14.11.

43. Malter AD, Larwon EB, Urban N et al. Cost-effectiveness of lumbar discectomy for the treatment of herniated intervertebral disc. Spine 1996; 21:10481055.

44. Lave JR, Frank RG, Shlchulber HC et al. Cost effectiveness of treatments for major depression in primary care practice. Arch Gen Psychiatry 1998; 55:645-651.

45. Manchikanti L, Pakanati RR, Pampati V. Comparison of three routes of epidural steroid injections in low back pain. Pain Digest 1999; 9:277-285.

46. Manchikanti L, Pakanati RR, Bakhit CE et al. Role of adhesiolysis and hypertonic saline neurolysis in management of low back pain. Evaluation of Modification of Racz Protocol. Pain Digest, 1999; 9:91-96.

47. Manchikanti L, Pakanati RR, Bakhit CE, et al. Nonendoscopic and endoscopic adhesiolysis in post lumbar laminectomy syndrome. A one-year outcome study and cost effectiveness analysis. Pain Physician 1999; 2:52-58.

48. Kloth DS. Taking from Peter and giving to Paul. ASA newsletter 2000; 64 (3):35. 